\section{Feminismo, educación y democracia en}

\section{Chile \\ (1872-1925)}

Feminism, education, and

democracy in Chile(1872-1925)

Feminismo, educação e

democracia no Chile (1872-1925)

\section{Alejandra Castillo*}

* Docente e investigadora, Universidad de Artes y Ciencias sociales, ARCIS, Santiago, Chile. Doctora en Filosofía Universidad de Chile. Correo electrónico: alejandrabcastillov@hotmail.com

\section{Resumen}

El artículo muestra cómo la relación entre educación y democracia es clave para comprender, en perspectiva histórica, la presencia de la mujer en la esfera de lo político. Con la instauración del derecho a la educación para las mujeres chilenas a partir de 1915, se sientan las bases para la construcción de un nuevo espacioen-común y para la redefinición de la igualdad: No hay diferencias, ni exclusiones, mujeres y hombres son iguales en el espacio de la escuela; sin embargo, las mujeres seguirán siendo excluidas en el ámbito de lo político.

\section{Palabras clave}

Mujeres, política, educación, derechos, Chile.

\section{Abstract}

This article shows how the relation between education and democracy is remarkable, in order to understand, in a historical perspective, the presence of woman in politics. With the establishment of the right to education for Chilean women from 1915, bases for making of a new niche in common, and for a redefinition of equality are set: There are no differences, nor exclusions, both men and women are equal at the school's niche; however, women will follow being excluded in the field of politics.

\section{Key words}

Women, politics, education, rights, Chile.

\section{Resumo}

O artigo explica que a relação entre educação e da democracia é essencial para a compreensão - na perspectiva histórica- a presença das mulheres no campo da política. A introdução do direito à educação para as mulheres no Chile a partir de 1915 prepara o terreno para construir um novo espaço em comum e redefinir a igualdade: não há diferenças nem exclusões. Mulheres e homens são iguais no espaço escolar; no entanto, as mulheres continuam a ser excluídas da esfera política.

\section{Palavras-chave}

Mulheres, política, educação, direitos, Chile.

Fecha de recepción: 23 de marzo de 2010 Fecha de aprobación: 19 de octubre de 2010

Pedagogía y Saberes No.33. Universidad Pedagógica Nacional Facultad de Educación. 2010, pp. 73 - 82 
Chile, el reclamo feminista por una ciudadanía activa se encuentra fuertemente entretejido con el reclamo por el derecho igualitario a la educación. Ya a comienzos de siglo veinte, la exigencia de los derechos de participación política se asocia a la exigencia de la emancipación intelectual, del derecho a pensar y de actuar por sí misma -¡Sapere Aude! pareciera oírse en ese entonces, tras las peticiones de las mujeres de finales de siglo decimonónico-. No quieren tan sólo votar y regir el destino de su país; quieren, también y sobre todo, regir el destino de sus propias vidas. De ahí que ensayen tan diversos caminos como el seguido por Martina Barros al traducir el texto de John Stuart Mill TheSubjection of Women en 1872 o los seguidos por las educadoras del siglo XIX Isabel Le-Brun y Antonia Tarragó, quienes propugnaron por la necesidad de dar a las mujeres una educación completa y no marcada por la diferencia sexual.

\section{"En Chile, el reclamo feminista por una ciudadanía activa}

se encuentra fuertemente entretejido con el reclamo por el derecho igualitario a la educación. Ya a comienzos de siglo veinte, la exigencia de los derechos de participación política se asocia a la exigencia de la emancipación intelectual, del derecho a pensar y de actuar por sí misma...”

Así, para la época, las mujeres asimilan el ideal republicano de democracia al de demopedia ${ }^{1}$. De este modo, cuanto más urgente se vuelve el ejercicio verdadero del sufragio universal tanto más necesario se hace para las mujeres su inclusión al sistema educativo en todos sus niveles. El ejercicio democrático del sufragio universal presupondrá no solamente las libertades fundamentales, sino también la igualdad

1 Al respecto puede recordarse que ya en los primeros esbozos constitucionales estaba presente la idea de hacer de la educación un derecho otorgable a hombres y mujeres, aunque, cabe señalar, diferenciado en términos sexistas. Así, por ejemplo, se lee en el Proyecto de Constitución para el Estado de Chile, redactado por Juan Egaña en 1811, el artículo 216 que señala: "En las atenciones del Instituto Nacional debe comprenderse, sobre todo, un colegio de mujeres donde, a más de la educación e instrucción nacional proporcionada, aprendan los oficios y artes más compatibles con su sexo”. del derecho a la educación. Por ello no es de extrañar que para la temprana fecha -tanto para Chile y como para América Latina- de 1877 el presidente chileno, Aníbal Pinto, y el Ministro de Educación Pública del periodo, Miguel Luís Amunátegui, otorgaran a las mujeres el derecho de ingreso a todas las carreras universitarias mediante el decreto que señalaba: " 1 은 conviene estimular a las mujeres a que hagan estudios serios y sólidos; $2^{2}$ que ellas puedan ejercer con ventaja algunas de las profesiones denominadas científicas; $3^{\circ}$ que importa facilitarles los medios de que puedan ganar la subsistencia por sí mismas. Se declara que las mujeres deben ser admitidas a rendir exámenes válidos para obtener títulos profesionales, con tal que ellas se sometan para ello a las mismas disposiciones a que están sujetos los hombres" (Letelier, 1892, p. 142).

Ilustrar e instruir se reconocen, entonces, como términos claves para la emergencia de la mujer en la esfera de lo político. A través del ideal ilustrado de la "educación para todos" se comenzará a construir un nuevo espacio-en-común desde donde se mostrará la injusticia de no ser parte de la comunidad política. Si, en última instancia, la diferencia sexual se constituye en el mecanismo que ha de permitir a algunos acceder a los derechos políticos, mientras que a otros los relega fuera de los márgenes de lo público en calidad de menores de edad, la educación general e indiferenciada se instaurará, no obstante, como aquel lugar en común, el lugar de la igualdad; en fin, como el punto de coincidencia entre la existente distribución de los lugares y las funciones y la redefinición polémica de aquellos lugares y funciones por la emergencia de un grupo -en este caso las mujeres, que exigirá su reconocimiento como ciudadanas con plenos derechos-. La igualdad, de este modo, se redefinirá en el terreno de la educación. De la mano de Valentín Letelier, y de otros antes que él, se pedirá una instrucción general destinada indistintamente a hombres y mujeres puesto que ya "no se podría aducir razón alguna siquiera sea de mediano peso para justificar la práctica común de dar una educación a un sexo y otra radicalmente diversa a otro. Si el hombre necesita vigorizar sus facultades también necesita vigorizar las suyas la mujer" (Labarca, 1942, p. 9).

Es de suma importancia anotar que las feministas de comienzos del siglo XX harán suya la tradición republicana en lo relativo a la educación; tradición en la cual anclarán las bases de su discurso de emancipación política. En una revisión de la historia de la educación femenina en Chile, la educadora y feminista Amanda Labarca reconstruirá, a su vez, la historia republicana chilena y pasa revista a nombres como el Fraile de la Buena Muerte, Camilo Henríquez, Juan 
Egaña, Andrés Bello, Lastarria y Mariano Egaña. Además, en un gesto de muy buen gusto, incorporará a su discurso emancipatorio, que no es otro que el de igualdad, las palabras de Miguel Luís Amunátegui cuando señala:

[...] existe en nuestro suelo un enemigo más formidable que una invasión extranjera, enemigo que nos tiene avasallados, que no nos deja respirar, que nos ata las manos, que no nos permite dar un paso en la senda del progreso sin que sintamos sus cadenas incorporadas a nuestro ser como las venas al cuerpo! Ese enemigo es la ignorancia, madre de la ineptitud para el trabajo, de la imprevisión para el porvenir, de la preocupación y los vicios. Es necesario, urgentísimo, que declaremos la guerra a ese enemigo doméstico con tanto tesón, con tanto entusiasmo, como se la hemos declarado, como se la declaremos a todo enemigo de la República (Labarca, 1942, p. 9).

Se desplazará, de esta manera, la desigualdad del plano de lo "natural", de lo biológicamente asignado, para entenderse como falta de educación. Amanda Labarca, y con ella las mujeres chilenas, redefinirá la desigualdad desde el prisma de la educación al desalojar los ya anticuados argumentos patriarcales que destinan a la mujer a ser la réplica defectuosa del hombre. La desigualdad no se teñirá más de diferencia sexual; será simple "ignorancia".

El juego entre lo idéntico y lo diferente, la alteridad, en fin, la propia diferencia de los sexos motivará la emergencia de una nueva escena; allí lo central se encontrará en una redefinición de la igualdad. Mas esta redefinición, al reinstalar de nuevo lo neutro, no buscará la eliminación de la marca primaria de la diferencia sexual; operará en un desplazamiento hacia el campo de la educación. Germinará en este ámbito un nuevo concepto de igualdad en el cual todos los sujetos estarán llamados a participar sin necesidad de "invisibilizar" la diferencia. Por ello, no se da una "guerra de los sexos", pero sí una "guerra a la ignorancia" (Labarca, 1942, p. 9). De ahí que el feminismo de comienzos del siglo XX esté representado notablemente por dos feministas y educadoras: Amanda Labarca y Gabriela Mistral. La primera, consciente de la redescripción de la igualdad, desde la forma de la educación dirá:

El problema de la educación femenina es actualmente uno de los más difíciles y complejos. Está ligado al futuro de la raza, de la familia, del hogar; a las necesidades de la nación y de la sociedad, y además debe contemplar las necesidades individuales de la mujer que necesita aprender a bas- tarse por sí misma espiritual y económicamente. La tendencia tradicional ha estimado indispensable subyugar durante siglos la libertad de la mujer a los designios colectivos de la especie; la tendencia moderna cree posible conciliar estas necesidades raciales con las aspiraciones de una personalidad independiente. Aquella ha intentado atrofiar a la mujer en beneficio de la madre; la segunda afirma que los mejores hijos nacerán de las mujeres más cultas, más razonadoras, más bien equilibradas. El campo de lucha de esta controversia es al presente la educación (Labarca., 1917, p. 127).

Labarca, influida por la visión de Letelier en lo relativo a la educación, abogará por una instrucción indiferenciada y alejada de los designios maternalistas que confinarían a las mujeres al abrasador calor hogareño. No sólo le preocupará la instrucción de las mujeres sino, por encima de todo, el tipo de formación recibida. Por tanto, no sólo es el hecho de asistir a las aulas, sino que se ha de asistir para recibir una educación que les permita valerse por sí mismas, que les permita pensar y actuar por sí mismas; en otras palabras, que les permita la emancipación.

El ideal republicano consigna la educación como un derecho ${ }^{2}$. Desde este telos republicano Amanda Labarca exigirá con fuerza la extensión de la enseñanza pública a todas las mujeres. Por ello, también, saludará favorablemente la idea de avanzada -gestada y concretizada a finales del siglo XIX- de crear liceos fiscales para mujeres. En este sentido reconoce la radical importancia de "la creación de los liceos fiscales de niñas [...] con la fundación del Liceo de Niñas №1, de Santiago, en 1895, al cual lo siguieron, al principio con timidez y luego con ímpetu avasallador, los cuarenta liceos femeninos que hoy existen en la República" (Labarca, 1947, p.133). De esta manera, con la incorporación de las mujeres al sistema público de enseñanza se desplaza completamente la diferencia de los sexos, en tanto marca de la exclusión, para redefinir efectivamente la igualdad en el plano de lo educativo.

A la fecha de 1915 el círculo se cierra. Las mujeres tendrán derecho a la educación. Se supera la instrucción "especial" para cada sexo. Existen escuelas y liceos fiscales para mujeres; y las puertas de la

2 Bien conocía Amanda Labarca las vertientes libertarias francesas de las cuales bebía el republicanismo chileno. Por ello no es de extrañar que su exigencia por una educación estatal e igualitaria encontrara fuerte respaldo en las palabras de Montesquieu: “c'estdans le gouvernementrépublicain que l'onabesoin de toute la puissance de l'éducation". Para una idea, en extenso, de la relación entre la educación y el gobierno republicano (Montesquieu,1758, p. 33). 


\section{"A la fecha de 1915 el círculo se cierra. Las mujeres tendrán derecho a la educación. Se supera la instrucción "especial" para cada sexo. Existen escuelas y liceos fiscales para mujeres; y las puertas de la Universidad están abiertas para ellas desde 1877."}

Universidad están abiertas para ellas desde $1877^{3}$. Las bases para la construcción de un nuevo espacioen-común y para la redefinición de la igualdad están dadas. No existen diferencias ni exclusiones; mujeres y hombres son iguales en el espacio de la escuela. En palabras de Amanda Labarca: "ni legal ni prácticamente existen obstáculos para el ascenso de la mujer por los senderos de la educación" (p. 134).

Desde este nuevo espacio de igualdad, las mujeres intentarán mostrar la contradicción que implica tener acceso al sistema educativo en todos sus niveles; aspecto que, potencialmente, les permitirá formar parte de la comunidad como profesionales y no ser consideradas como ciudadanas activas, esto es, como ciudadanas con derecho a voto. Contradicción que posibilitará, entre otras cosas, la formación de profesionales que verán coartadas sus potencialidades por el simple hecho de ser mujeres. Sin ir más lejos, por ejemplo, abogadas que no podrán ser testigo ni acceder a cargos como los de martillero, notario o corredor y, por supuesto, imposibilitadas a optar a la totalidad de los cargos públicos por no ser ciudadanas electoras (Klimpel, 1962, p.52).

Si la educación propicia un contexto en el cual la diferencia de los sexos deja de ser pertinente, ¿por qué nuevamente se introduce la marca de los sexos para excluir a las mujeres de lo público? En búsqueda de una respuesta a aquella pregunta y en

3 Para tener una idea de la cantidad de mujeres que recibían educación estatal en Chile puede tomarse como referente el año de 1920. Para esa fecha las escuelas primarias atendían a 125.028 estudiantes; en tanto, los liceos secundarios, 9035. En lo relativo a las carreras universitarias el instituto pedagógico recibía 568 alumnas; el instituto de educación física, 197; la escuela de medicina, 36; la escuela de farmacia, 118; la escuela de leyes, 12; las escuelas de escultura, pintura y arte decorativo, 771 estudiantes; y el conservatorio de música, 670 (Labarca, 1923, p. 143). atención al nuevo espacio de igualdad ganado, diversos grupos de mujeres se organizarán para reclamar por sus derechos cívicos. He aquí un desplazamiento: de la igualdad en la educación a la igualdad cívica; y, también, un cambio de énfasis: del establecimiento de una demopedia se exigirá, ahora, la democracia. Labarca advertirá este cambio de énfasis cuando indica que:

[...] desde 1915 la lucha se desplaza hacia las reivindicaciones legales. El 17 de junio de ese año iniciamos las labores de la primera sociedad íntegramente formada por mujeres y que pretendía alcanzar por el medio del esfuerzo de todas, la elevación colectiva. Fue el Círculo de Lectura. El Club de Señoras, se formó inmediatamente después. El consejo Nacional de mujeres, fundado en 1919, se preocupó de la obtención de una mayor justicia social para la mujer. Como su presidente, nos cupo tomar la iniciativa de solicitar explícitamente los derechos civiles y políticos (Labarca, 1947, p. 134).

De las demandas por el derecho a una educación igualitaria, las mujeres de comienzos de siglo pasarán a una segunda fase: la redefinición de su reclamo igualitario en el campo de la política. Esta redefinición implicará no sólo la emergencia de las mujeres en la escena pública sino que también sacará a la luz la aporética lógica que anima al ideario republicano chileno que declara por un lado la igualdad de los sujetos basada en la educación, mientras que, por otro, los excluye de la vida cívica. ¿Es posible poner fin a esta aporía? Aparentemente sí, aunque su solución lleve a una difícil disyuntiva: el rechazo del telos republicano o la incorporación a pesar de la pérdida que conlleva la asimilación a un discurso universalista. Dicho de otro modo, la solución señala dos posibles alternativas: evidenciar el engaño y desestimar por inviable el ideal democrático o creer firmemente en el espacio de igualdad creado por la educación y desde ahí reclamar por la inclusión política. 
Las mujeres de comienzos de siglo optarán por la segunda de las anteriores salidas. Mujeres y hombres tienen algo en común: la educación. Mujeres y hombres detentan iguales capacidades y formación para ser parte de la comunidad en tanto ciudadanos. De esta forma, las mujeres redefinirán el espacio de lo político y harán emerger, a su vez, la política -la división- para demostrar el malentendido (o desorden como lo llamaría Geneviève Fraisse) de ser parte de la sociedad y no ser reconocidas como miembros de ella.

"Tomar la palabra para tomar los derechos. A la manera de los actos de habla, al decir se hacen cosas, muta la realidad. El decir de las mujeres en traducciones, artículos y conferencias interrumpe la normalidad de la ley del habla masculina y hace posible la emergencia de la mujer como un sujeto público."

De aquí en más se delineará la petición democrática de las mujeres. Pretensión que se expresará en la formación de grupos feministas, en la publicación de artículos relativos al derecho a sufragio o mediante conferencias. En relación a este último aspecto, conocida es el discurso ofrecido por Martina Barros en el Club de Señoras de Santiago acerca del voto político femenino. En tal disertación, hace explícita la lógica sexual que determina la exclusión política de las mujeres e indica, además, que "se ha dicho y se repite mucho que no estamos preparadas para esto, ¿qué preparación es esa que tiene el más humilde de los hombres con el solo hecho de serlo y que nosotras no podamos alcanzar?, la he buscado y no la puedo descubrir" (Barros, 1917).

El espacio público abierto, en debate y reclamado por las mujeres, el ejercicio de tomar la palabra públicamente altera, sin duda, la normalidad de lo político en tanto que se introduce una otra voz que pone en tela de juicio la naturalidad de la exclusión. No hay más "lo natural" sino espacios de reconfiguración y transformación de lo público. Este reclamo democrático no sólo es importante en la medida que logra visibilizar y dar existencia a un sector antes relegado en la vida cotidiana de la familia; su relevancia radica en el hecho de poner en tensión lo naturalmente aceptado; se conflictúa así la ordenación jerárquica de lo social, el clericalismo, la división sexual del trabajo, el concepto de ciudadanía, la idea de igualdad jurídica y también, por supuesto, la propia idea de democracia.
Tomar la palabra para tomar los derechos. A la manera de los actos de habla, al decir se hacen cosas, muta la realidad. El decir de las mujeres en traducciones, artículos y conferencias interrumpe la normalidad de la ley del habla masculina y hace posible la emergencia de la mujer como un sujeto público. La voz de la mujer en la vida política, en encarnación del ideal republicano del vivere civile, ha producido efectos; sin embargo, aún falta lo buscado desde 1875: los derechos cívicos.

Las mujeres quieren entrar en la vida pública de hecho y derecho. A partir de ese deseo, curiosamente el partido conservador hace eco y elaborará el primer proyecto de ley para conceder a las chilenas los derechos de ciudadanía. La iniciativa se presenta en 1917 ante la cámara de diputados. Amanda Labarca destaca la relevancia de este proyecto:

Cuand o se escriba la historia del movimiento femenino chileno, este año de 1917, aparecerá ante la observación del estudioso con caracteres reveladores. En él, la fracción joven del partido conservador formula un proyecto de ley para conceder a las mujeres los derechos cívicos de la ciudadanía activa; en él, la representación parlamentaria radical propone otro para libertar a los cónyuges de los vínculos de un matrimonio indisoluble, y aunque ninguno de los dos haya tenido los caracteres de un ataque real a las trincheras seculares, sino más bien de simple escaramuza entre patrullas de avanzadas, los dos han levantado discusiones que han servido para dar a las mujeres conciencia de su precaria situación, y-lo que es mucho más importante- para ponerlas de acuerdo sobre puntos capitales que van a ser la plataforma de las aspiraciones femeniles en un futuro cercano (Labarca, 1934, pp. 126-127).

4 Para otras genealogías del movimiento de mujeres y feminista en Chile, ver: Covarrubias, P. (1981), El movimiento feminista chileno, Documento de Trabajo, Academia de Humanismo Cristiano, Círculo de la condición de la mujer; Kirkwood,J. (1982, mayo), Ser política en Chile: las feministas y los partidos, Documento Flacso, Núm. 143, Santiago; Kirkwood,J. (1982, octubre), Feminismo y participación política en Chile, Documento Flacso, Núm. 159, Santiago; Gaviola, E. et al., (1986), "Queremos votar en las próximas elecciones". Historia del movimiento femenino chileno 1913-1952, La morada/CEM, p. 17;Kirkwood, J. (1986), Ser política en Chile. Los nudos de la sabiduría feminista, Santiago, Cuarto Propio; Eltit,D. (1993), Elena Caffarena: el derecho a voz, el derecho a voto, Cuadernos de Chile, Núm. 50, Ciudad de México, Casa de Chile en México; Verba, E. (1995), "El círculo de lectura y el club de Señoras de Santiago (1915-1920)", en: Journal of Women's History 7, Núm. 3, pp. 6-33; Rosemblatt, K. (1996), Gendered Compromises: Political Cultures, Socialist Politics and the State in Chile, 1920-1950, Dissertation, Madison, University of Wisconsin; Antezana-Pernet,C. (1997), El Memch hizo historia; Antivilo, J. y Vitale, L. (2000) Belén de Sárraga. Precursora del feminismo Latinoamericano, Santiago, Cesoc; Castillo, A. (2005), La república masculina y la promesa igualitaria, Santiago, Palinodia; Lavrín, A. (2005) "Política y sufragio 
Aunque de nuevo se margine a la mujer de la República, se ha creado, sin embargo, un nuevo espacio político-social en el cual se hace factible formular, con sentido, un petitorio para la incorporación de la mujer a la vida cívica. Existe, en otras palabras, un espacio de comprensión mutua. El habla de las mujeres no es más el habla del desorden, sino que se comparte el mismo juego de lenguaje: el lenguaje de la democracia.

Es cierto, a las mujeres le son negados sus derechos cívicos; pero, sin embargo, el rechazo ya no obedece a razones biológicas: se ha desplazado a un terreno jurídico. Las mujeres han construido un espacio en común, un espacio de comprensión de sentido; es decir, una igualdad básica. Desde allí se exigirá el derecho a la inclusión política.

Desde este lenguaje en común que ha otorgado la educación, el reclamo democrático de las mujeres se formulará luego en el terreno de las leyes. En pos de esta redefinición en 1919 se fraccionará el Círculo de Lectura y se dará lugar a dos nuevas instituciones que trabajarán "bajo las banderas de un feminismo decidido": El consejo Nacional de Mujeres y el Círculo Femenino de Estudios (Labarca, 1947, p. 146). El objeto central de ambas agrupaciones será la obtención de todos los derechos políticos y civiles de la mujer, leyes de divorcio, leyes de protección a la obrera, leyes de protección a la madre, entre otras (Labarca,1947, p. 135). Con miras a conseguir los anhelados derechos cívicos, ambos centros presentan al Congreso, infructuosamente, en 1922 un proyecto de ley que otorgara los derechos cívicos y políticos a las mujeres. Amanda Labarca, presidenta del Consejo Nacional de Mujeres, señala la importancia de ese momento al indicar que:

"El año 1922 ha visto a estas dos últimas instituciones trabajar afanosamente en preparar a la opinión pública para la concesión a la mujer de sus derechos civiles. Existen presentados al Congreso Nacional, varios proyectos que mejoran la condición legal femenina que, en sus grandes rasgos es la misma derivada del Código Napoleón, que rige en Francia y en la mayoría de los países latinos y sudamericanos" (1947, p. 146).

Con este mismo objetivo surgen varios grupos de mujeres al amparo de diversos sectores políticos y sociales. Así, en 1920 se forma la Gran Federación Femenina de Chile auspiciada por la Federación Obrera; en el mismo año se formarán la Unión Obrera

Femenino en Chile", en: Mujeres, feminismo y cambio social en Argentina, Chile y Uruguay 1890-1940, Santiago, Centro de Investigaciones Barros Arana, Dibam, pp. 361-404; Barros, M. (2009), La esclavitud de la mujer (notas y estudio crítico de Alejandra Castillo), Santiago, Palinodia.
Femenina y el Consejo Federal Femenino; en 1922 se creará el Partido Cívico Femenino; a su vez en 1922 se dará origen a la Juventud Católica Femenina; en 1924 se formará el Partido Demócrata Femenino. Paralelo a la formación de estas agrupaciones se celebrarán en Santiago de Chile el Congreso Panamericano de Mujeres (1922) y la Conferencia Panamericana de Mujeres (1923) (Gaviola, 1986, p. 35).

Esta es la escena política-social de las mujeres en la crucial fecha de 1925. Crucial, al menos, por dos aspectos. Primero, durante el período aquí estudiado no sólo las mujeres toman consciencia de su rol político y la necesidad de ser consideradas como sujetos activos a la hora de decidir acerca del destino de la república sino que también este reclamo democrático se expresa por casi la totalidad de la fuerzas vivas de la sociedad -se incluyen aquí los sindicatos obreros, la federación de estudiantes, las agrupaciones de profesionales, la liga Nacional del magisterio y la Federación de clases medias, entre otros-. En fin, las bases sociales en su conjunto se sienten llamadas a formar parte de la comunidad en tanto "sujetos deliberantes". En segundo lugar, paralelo a la reconfiguración del espacio público con la emergencia de nuevos grupos sociales se hace evidente la crisis política, administrativa y social por la que atraviesa el país. Debido a estos dos factores, y con algún afán de justificación de su propio proyecto político, Arturo Alessandri, Presidente de Chile en el período, convocará a la elaboración y aprobación de una nueva Constitución: la Constitución de 1925.

\section{"Desde este lenguaje en común} que ha otorgado la educación, el reclamo democrático de las mujeres se formulará luego en el terreno de las leyes. En pos de esta redefinición en 1919 se fraccionará el Círculo de Lectura y se dará lugar a dos nuevas instituciones que trabajarán "bajo las banderas de un feminismo decidido": El consejo Nacional de Mujeres y el Círculo Femenino de Estudios."

Al llamado del Presidente para la elaboración de una nueva carta fundamental se unen voces que piden convocar a una Asamblea Constituyente en la cual participasen todas las fuerzas vivas de la sociedad. No se quiere una asamblea de juristas, ni de notables 
ciudadanos, ni de partidos. Todos los sujetos, en tanto miembros de la comunidad política, están llamados a participar en la elaboración del documento que regiría la vida cívica del país. En este sentido, "reclamaban la constituyente, las colectividades de la alianza, radicales y democráticos. Y la solicitaban además las fuerzas estudiantiles y obreras -comunistas, FOCH, FECH, etc.- del alessandrismo popular, agrupados en el 'Comité Ejecutivo Nacional Obrero' [...] El propio mandatario anunció la constituyente en el telegrama de Roma" (Gonzalo, 1981, p. 532). La reclaman, a no dudar, también las mujeres que ven en ella el momento de hacer visible su petición de igualdad y con ello construir una república democrática de verdad (Labarca, 1947, p. 140).

Confiados en que Alessandri convocará a una Asamblea Constituyente que reuniría todas las fuerzas vivas de la Nación y con la creencia, a su vez, en el ideal democrático de la participación activa de todos los ciudadanos -y haciendo suyo el discurso republicano de la igualdad- el $1^{\text {o }}$ de febrero de 1925 el Comité Nacional Obrero convoca a un congreso Constituyente de Asalariados e Intelectuales a realizarse en el mes de marzo del mismo año. Asimismo, se dan a conocer las bases para su participación: "en su artículo primero, se convocaba a los representantes de los proletarios (45\%), empleados (20\%), profesores (20\%), estudiantes (7\%), y profesionales e intelectuales (8\%) (No se aprobó una moción de incluir a 25 delegados de las fuerzas armadas). Nadie podría asistir al congreso como político o representante de partido político" (Salazar, 1992, p. 133). Como objetivo principal para la realización de este congreso se reconoce, sin lugar a dudas, el "de concretar en un proyecto de Constitución Política de Chile las aspiraciones del proletariado y los intelectuales que simpaticen con los modernos principios de justicia y solidaridad" (Salazar, 1992, p. 133).

Establecidos los posibles participantes y los objetivos, entre los días 8 y 11 de marzo de 1925 en el Teatro Municipal de Santiago se celebra la Asamblea Constituyente de Trabajadores e Intelectuales. Ésta convoca alrededor de 2.050 delegados de todo el país e involucra a un amplio espectro de la sociedad chilena de la época. Se destacan, entre otros participantes, los comunistas Manuel Hidalgo, Salvador Barra, Ramón Sepúlveda, Carlos Alberto Sepúlveda, Carlos Contreras Labarca, y Galvarino Gil; los anarquistas Carlos Alberto Martínez, Alejandro Escobar y César Godoy Urrutia; los miembros de la FECH, Enrique Rossel, Carlos Vicuña, Alfredo Demaría, Julio Barrenechea, Oscar Schnake y Eugenio Gonzalez; las feministas Amanda Labarca, Gabriela Mandujano y Ernestina Pérez; las delegadas del Movimiento Cívico
Femenino Bertina Pérez, Isabel Díaz y Berta Recabarren; los maestros, pertenecientes a la "Asociación General”, Luis Gómez Catalán, David Naveas y Victor Troncoso; y los pintores Benito Rebolledo y Julio Ortiz de Zárate (Ortiz, 2002, p. 59).

Así, las fuerzas vivas de la sociedad, en su conjunto, se dan cita para sentar las bases de la próxima Constitución. Este hecho se ve por sus propios actores como el nacimiento de la verdadera república en la que todos y cada uno de los ciudadanos tuviese la oportunidad de participar en su construcción. Evento que se consigna en un periódico obrero de la siguiente manera:

[...] es sin duda alguna esta reunión las más importante de cuantas se han celebrado en Chile, desde el nacimiento de la república, por cuanto ella congregará la representación genuina de los elementos de trabajo convocados por sí mismos para deliberar sobre las bases que han de darse a la sociedad en que viven, sin la intervención de otros elementos ajenos a los grandes intereses colectivos que representan, como lo han sido hasta hoy los congresos formados por diputados y senadores cuyos cargos representativos han sido el fruto del cohecho o de la violencia de la autoridad puesta a su servicio (Diario Justicia, 1925, p.11).

Cabe destacar, aquí, que el imaginario republicano ya no consiste solo en un discurso privativo de la clase política dirigente: se ha vuelto el ideal político de todo un pueblo. Se ha erigido, en otras palabras, como el discurso que hace factible la propia idea de la inclusión política y, con ella, la de la participación en lo público. Así resuena con fuerza, por ejemplo, la intensión de legislar en pro de los "grandes intereses colectivos" en desmedro, y denuncia, de servirse de la política para fines privados "frutos del cohecho y la violencia". Aunque sin explicitar, hacen suya la idea de virtud republicana en tanto la sobrevaloración de los intereses públicos antes de los privados. Entienden la virtud cívica como "el amor a la patria, entendiéndolo, no como una vinculación a la unidad cultural, étnica y religiosa de un pueblo, sino como amor a la libertad común, apoyado en instituciones con una historia particular, que tiene para ese pueblo un significado, o significados particulares que inspiran y a cambio se sustentan en una forma de vida y culturas particulares" (Viroli, 1997, p. 29). Por ello no es de extrañar que así también la comprendan, quienes a nuestro juicio son, las dos más importantes figuras críticas para la construcción de la escena política de comienzos de siglo: Luís Emilio Recabarren y Amanda Labarca. Ambos impregnados del discurso republicano vincularán, de modo explícito, la idea de virtud a la de amor (caritas) a la patria; el primero en Patria 
y patriotismo (1920) y la segunda en El patriotismo y el amor a la humanidad no se excluyen (1919).

De este modo, el ideal republicano plasmado en las previas constituciones no se puede considerar más como letra muerta sino que se ha transformado en el ideal desde el cual se entiende la política y desde el cual se apela para exigir participación en la res publica (Heise,1996). Desde él, sin lugar a dudas, apelarán también las mujeres para su inclusión en la vida política. De ahí su asistencia y activa participación en la auto-convocada Asamblea Constituyente de Obreros e Intelectuales de 1925 donde pedirán el reconocimiento de la injusticia de no ser ciudadanas. En relación con esta temática, un diario de la época recoge la siguiente observación: "la señorita María Teresa Urbina, la que con palabras elocuentes, pide a los constituyentes den capital importancia a los derechos de la mujer, colocándola en igualdad de condiciones con el hombre. Señala que "no es aceptable que los hombres de este siglo mantengan a la mujer en el estado de abyecta esclavitud en la que vegetó en la edad antigua y media" (Diario Justicia, 1925, p.2).

Igualdad, educación, participación política (vivere civile) conceptos que no sólo tienen existencia en los acalorados discursos expuestos entre los días 8 y 11 de marzo de aquel 1925, sino que se plasman en la propuesta que debía servir de base para la elaboración de la nueva Constitución Política de Chile. No está demás mencionar que tal propuesta deja traslucir la influencia del ideario republicano, al menos en los siguientes puntos: 10 "la República de Chile será federal; $2^{\circ}$ se procederá a la absoluta separación de la iglesia del Estado; $3^{\circ}$ El Estado debe proporcionar los fondos para la enseñanza pública, que debe ser gratuita desde la escuela primaria hasta la universidad; $4^{\circ}$ debe declararse la igualdad de derechos políticos y civiles de ambos sexos; 5ํㅡㄹ debe suprimirse el ejército permanente (Diario Justicia, 1925, pp.14-15).

La Constitución política de Chile se aprueba el 30 de agosto de 1925. Para su elaboración se forma una comisión consultiva compuesta por 122 destacados ciudadanos; sólo son convocados destacados hombres, pero no destacadas mujeres (pareciera escucharse: los hombres escriben las leyes, las mujeres urden las costumbres). Esta comisión se divide en dos sub-comisiones: una encargada de las reformas constitucionales que se propondrían a la constituyente y la otra para analizar el modus operandi de la propia asamblea constituyente. La segunda subcomisión bautizada como la "gran comisión consultiva" jamás sesiona. Mientras que la pequeña, la encargada de las modificaciones constitucionales, se reúne 33 veces para elaborar, en su totalidad, la nueva Carta
Fundamental ${ }^{5}$. La Constitución que se aprueba no incorpora ninguno de los principios emanados de la asamblea constituyente popular, a excepción de la separación de la iglesia del Estado. Las mujeres, y con ellas la igualdad, se excluyen de la res publica. José Guillermo Guerra, jurista integrante de la subcomisión que redactará el proyecto de Constitución, dirá al respecto:

[...] el texto actual de la Constitución dice lo mismo que la anterior, de modo que ha dejado la cuestión del sufragio femenino en la misma situación en que se encontraba. En la sesión 13aㅡ un miembro preguntó si las mujeres podrían ser elegidas para cargos legislativos y la sub-comisión estuvo conforme en que el texto constitucional no las excluía y en que el legislador era llamado a resolver la cuestión en definitiva. Algo semejante ocurrió en la sesión 30ạa, en la cual el Ministro de Justicia señor Maza, expresó el concepto de que la mente de la sub-comisión habría sido dejar al legislador la facultad de otorgar a la mujer, cuando lo estimara conveniente y oportuno, el voto municipal y también el político, opinión que no fue rebatida. Parece, pues, que predominó en la sub-comisión la idea de dejar a la ley la oportunidad de otorgar el derecho de sufragio a las mujeres (Guerra, 1925. pp. 83-84).

Reiteración del argumento, reiteración de la exclusión. Reiteración, no obstante, que conlleva un cambio. El cambio en lo idéntico. El "actual texto dice lo mismo que el anterior", nos dice el jurista, sin embargo, es radicalmente diferente. El discurso de emancipación de las mujeres que comienza a gestarse a mediados del siglo XIX hará emerger un nuevo espacio de igualdad desde el cual apelar a la hora de exigir por los derechos políticos. Ciertamente, este espacio-en-común era un impensado en 1833. Pero a la fecha de 1925 tanto el argumento de inferioridad biológica como el de inferioridad intelectual están desacreditados. No hay razón alguna para la exclusión de las mujeres de la vida política; sin embargo, son excluidas.

Se las excluye en la práctica, pero son incluidas bajo la sombra de la universalidad de la ley. Se las excluye, pero nuevamente queda abierta la promesa de la inclusión. Promesa graduada y progresiva

5 Cabe señalar que la sub-comisión "pequeña" quedó integrada por dos liberales unionistas (Pedro Nolasco Montenegro y Luís Barros), dos aliancistas (Domingo Amunategui y Eliodoro Yáñez), tres radicales (Enrique Oyarzún, Ramón Briones y Carlos Vicuña), un balmacedista (Héctor Zañartu), dos conservadores (Romualdo Silva y Francisco Vidal), un comunista (Manuel Hidalgo), un demócrata (Nolasco Cárdenas), un jurista (José Guillermo Guerra) y dos representantes de gobierno (Arturo Alessandri, Presidente de Chile, y José Maza, Ministro de Justicia). 
según la cual "se debe ir graduando la concesión de derechos políticos a las mujeres otorgándoles [...] 1 o el derecho a elegir en las municipales; $2 \stackrel{0}{ }$ el derecho de ser elegidas en las mismas; $3^{\circ}$ el derecho a elegir en las elecciones de Diputados, Senadores y Presidente de la República; 4ํe el derecho de ser elegidas para cargos legislativos, y de ser designadas como jurados; y 5o el derecho de ser nombradas Ministros de Estado o elegidas para el mando supremo de la Nación" (Guerra, 1925, p. 84).

El horizonte utópico otorgado por el ideario democrático se ha transformado, así, en una promesa graduada: en un juego de ensayo y error cuyas reglas se establecen por la república masculina.

\section{Bibliografía}

Barros, M. (1917), "El voto femenino”, en: Revista Chilena de Santiago, Chile.

Diario Justicia, Santiago, 1925, p.11.

Egaña, J. (1813), Proyecto de una Constitución. Para el Estado de Chile, Santiago.

Gaviola, E.et al. (1986), "Queremos votar en las próximas elecciones”, en: Historia del Movimiento Sufragista chileno 1913-1952, Santiago, LOM Ediciones.

Guerra, J.G. (1929), La Constitución de 1925,

Heise, J. (1996), 150 años de evolución institucional, Santiago, Andrés Bello.

Klimpel, F. (1962), La mujer chilena, Santiago, Andrés Bello.

Labarca, A. (1917), “Nosotras”, ¿Hacia dónde va la mujer?, Santiago, Ediciones Extra, 1934.

Labarca, A. (1919), "El patriotismo y el amor a la humanidad no se excluyen”, en: Revista Juventud, Santiago, FECH.

Labarca, A. (1923), "Nuestras actividades femeninas", ¿A dónde va la mujer?, Santiago, Ediciones.

Labarca, A. (1942), "La educación en Chile”, Cursos y Conferencias, año XI, vol. XXII, Buenos Aires.
"El discurso de emancipación de las mujeres que comienza a gestarse a mediados del siglo XIX hará emerger un nuevo espacio de igualdad desde el cual apelar a la hora de exigir por los derechos políticos. Ciertamente, este espacio-en-común era un impensado en 1833. Pero a la fecha de 1925 tanto el argumento de inferioridad biológica como el de inferioridad intelectual están desacreditados."

Labarca, A. (1947), Feminismo Contemporáneo, Santiago, Zig-zag.

Labarca, A. (1934), Feminsimo Contemporáneo, Santiago, Editorial Zig Zag, pp. 126-127.

Letelier, V. (1892), Filosofía de la educación, Santiago, Cervantes.

Montesquieu, (1758), De L'Esprit de Lois, Livre IV, Chap. V, Paris, ÉditionsGallimard, 1995.

Recabarren, L. E. (1920), Patria y patriotismo, Antofagasta, Universidad del Norte, 1972.

Salazar, G. (1992), Movimiento social y construcción de Estado: La Asamblea Constituyente Popular, Santiago, SUR, documento de trabajo.

Ortiz (2002), "Asamblea de Obreros e intelectuales de 1925", en: Crónica Anarquista de la subversión Olvidada, Santiago, Ediciones Espíritu Libertario.

Vial, G. (1981), Historia de Chile (1891-1973), Santiago, Zig- Zag.

Viroli, M. (1997), Por amor a la Patria: un ensayo sobre patriotismo y el nacionalismo, Madrid, Acento Editorial. 


\section{Revisión}

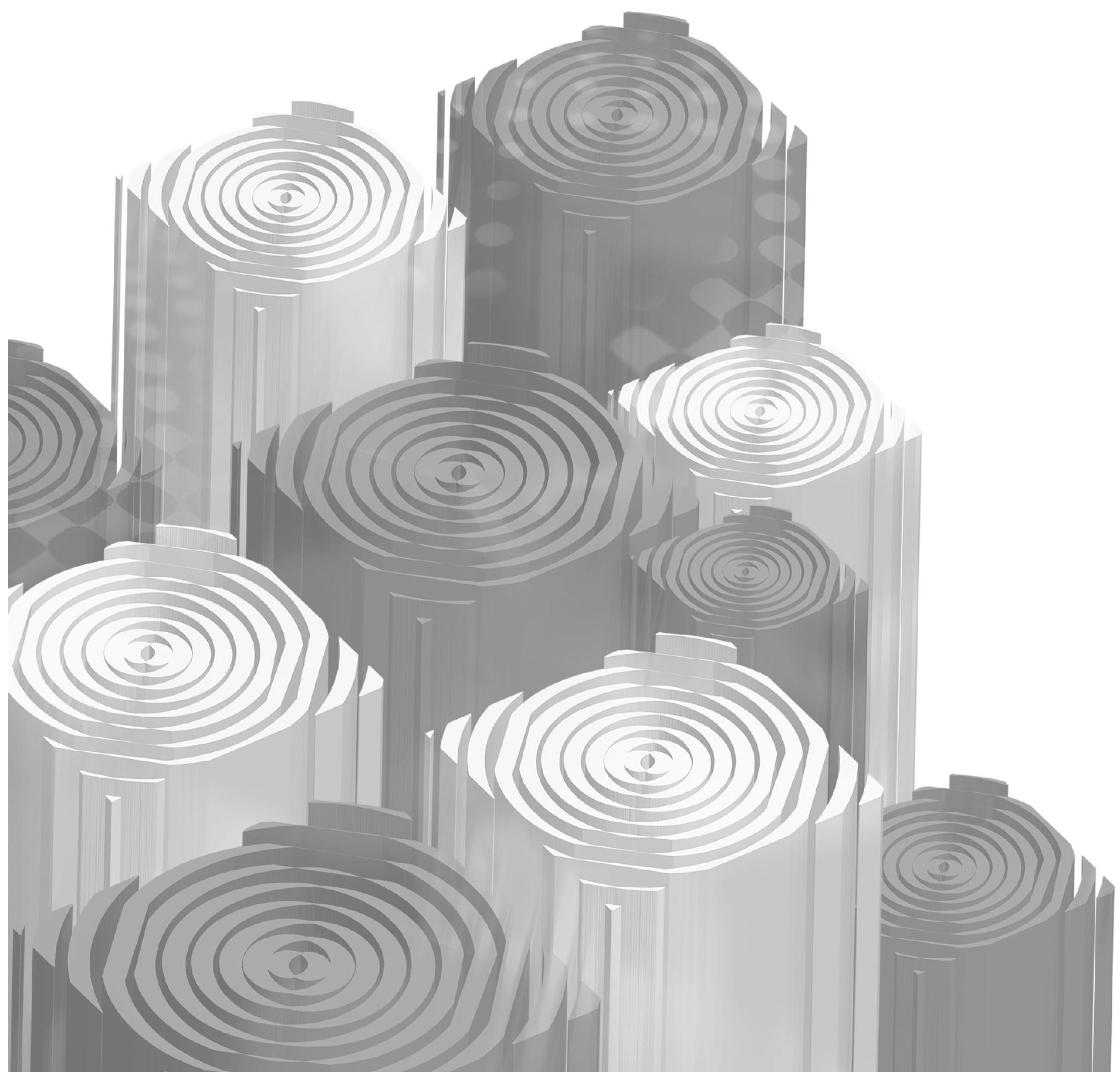




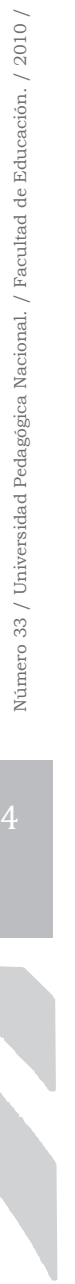

